\title{
Discussion on the management and control of urban waterfront space planning returning to the public
}

\author{
Hewang Wang, South China University of Technology, China \\ Chunyang Zhang, South China University of Technology, China
}

\begin{abstract}
Waterfront space is naturally public and high-value attraction, However, due to the shortcomings of its public guarantee mechanism, under the influence of market economy profit rules, the problems of private occupation of waterfront public space and irrational construction are widespread. Taking Guangzhou as an example, this paper selected representative water bodies at all levels for investigation, and found that these waterfront spaces have problems of access and use to a certain extent.In order to solve these problems, We aim to return the waterfront space to the public and take "people-oriented" as the technical basis, drawing lessons from the relevant research and practice of Shanghai's Huangpu River Pudong Coastal Through Project, Sanya River Waterfront Protection and Utilization, Chicago River Management and Control in the United States, and New York's Waterfront Space Planning Requirements, We put forward seven planning elements management and control strategies including traffic accessibility, visual accessibility, waterfront interface, waterfront mouth rate, waterfront retreat, waterfront height control, waterfront service functions and facilities, and further discussed the implementation of safeguard measures, in order to promote the planning and construction of waterfront public space back to the public.
\end{abstract}

\section{Keywords}

Waterfront public space, planning and control, returning to the public

\section{Introduction}

Hydrophilicity is human nature. Waterfront space, as a typical urban linear (ribbon) public space based on water resources such as rivers, lakes and streams (this paper does not discuss coastal space), Waterfront space promotes urban economic development (Liu,2018), improves urban image and quality, and promotes citizens' physical and mental health (Qian,2010), It is a shared place for urban residents to get close to nature and release their nature. With the return of waterfront space from production to life (Song,2010), people's requirements for the living environment are increasing, and they are also paying more and more attention to their own space rights and interests.

However, under the double mechanism of profit criterion of market economy and government land finance, the "growth machine" composed of government and developers accelerates the commercialization production of waterfront space, and the commercialization of space leads to the possession and monopoly of scarce waterfront space resources by a few dignitaries through value exchange(Song,2009), the privatization of waterfront space not only violates the public attribute of the essence of waterfront space, but also brings a series of spatial specific problems. 


\section{Questions raised}

\subsection{Field research}

Taking Guangzhou as an example, the author conducted classified investigation according to the grade and size of water body and the different land properties around waterfront space, including the Pearl River, secondary watercourses (shui dao) and small rivers (he chong). The surrounding land is mainly residential, commercial and multi-functional. (Fig. 1)

(1) Shamian island

This island is a 5A scenic spot, which is located in the west of Guangzhou City, surrounded by water on all sides, with sufficient waterfront space resources. The waterfront space has the following problems:

- Strong capital entry - privatization of waterfront space of a hotel.

- Interference of traffic construction on public space - the inner ring road passes close to the north side of the island in the form of viaduct, which has a negative impact on the waterfront landscape. At the same time, there is an obvious sense of depression under the viaduct and an obvious sense of obstruction to the sight line of the landscape.

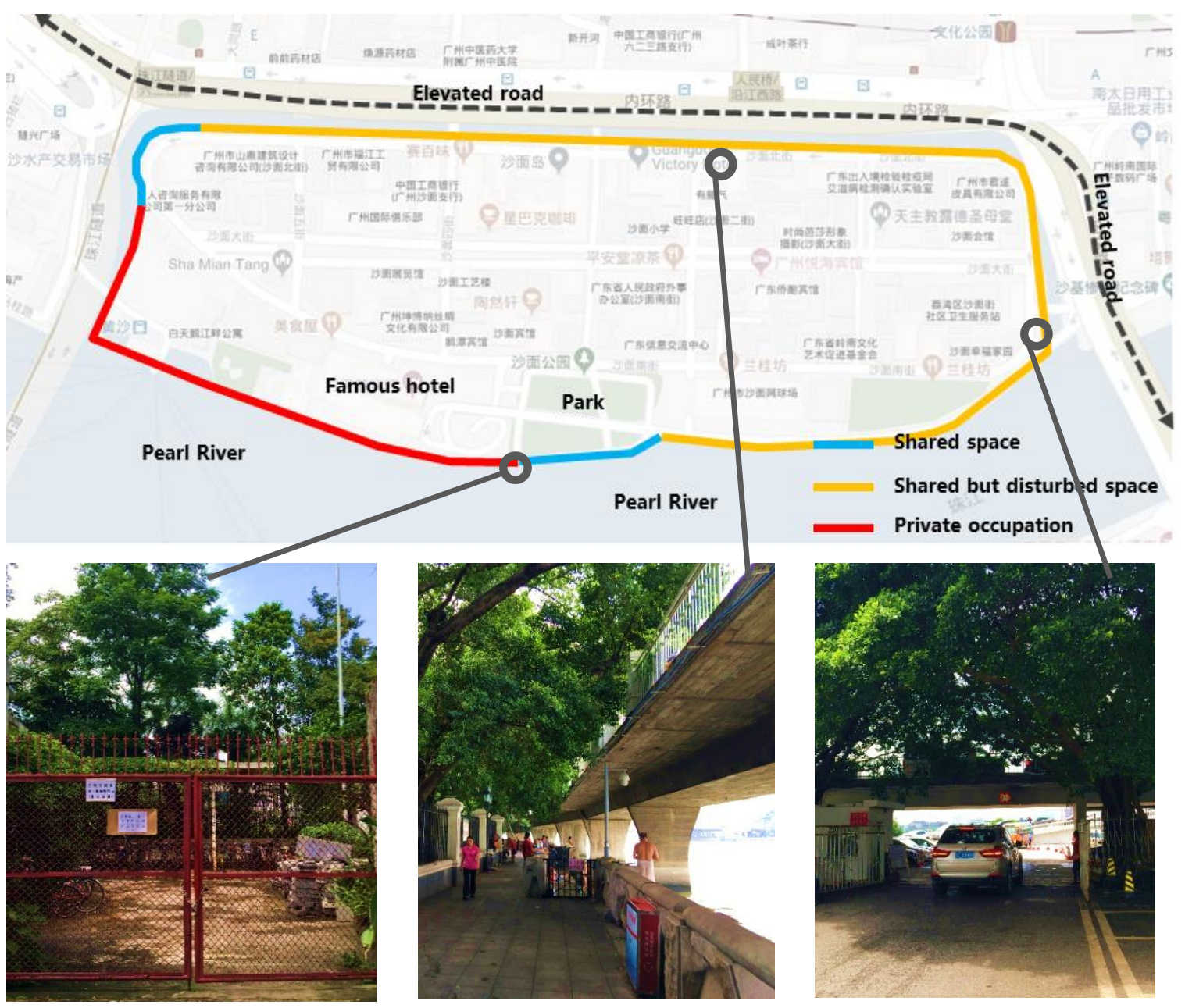

Figure 1. Waterfront space of Shamian island 1. Source: Author self-drawn.

(2) Dashi river

This area is mainly composed of two residential areas, the north and east of which are respectively adjacent to secondary waterways. Residential area 1 is an open residential area, and residential area 2 is 
a closed residential area. The open residential area has no fence facilities, and the waterfront boundary is well shared. The fence barrier of the closed residential area has brought about the barrier and closure of the waterfront space. (Fig.2)The specific problems of the waterfront space include:

- Space separation of closed residential areas - Taking the waterfront coastline for their own use, which is exclusive and blocks the continuity of waterfront space.

- Improper scale of some open waterfront space - the pedestrian activity space in the waterfront space is too narrow to meet the needs of traffic and activities.

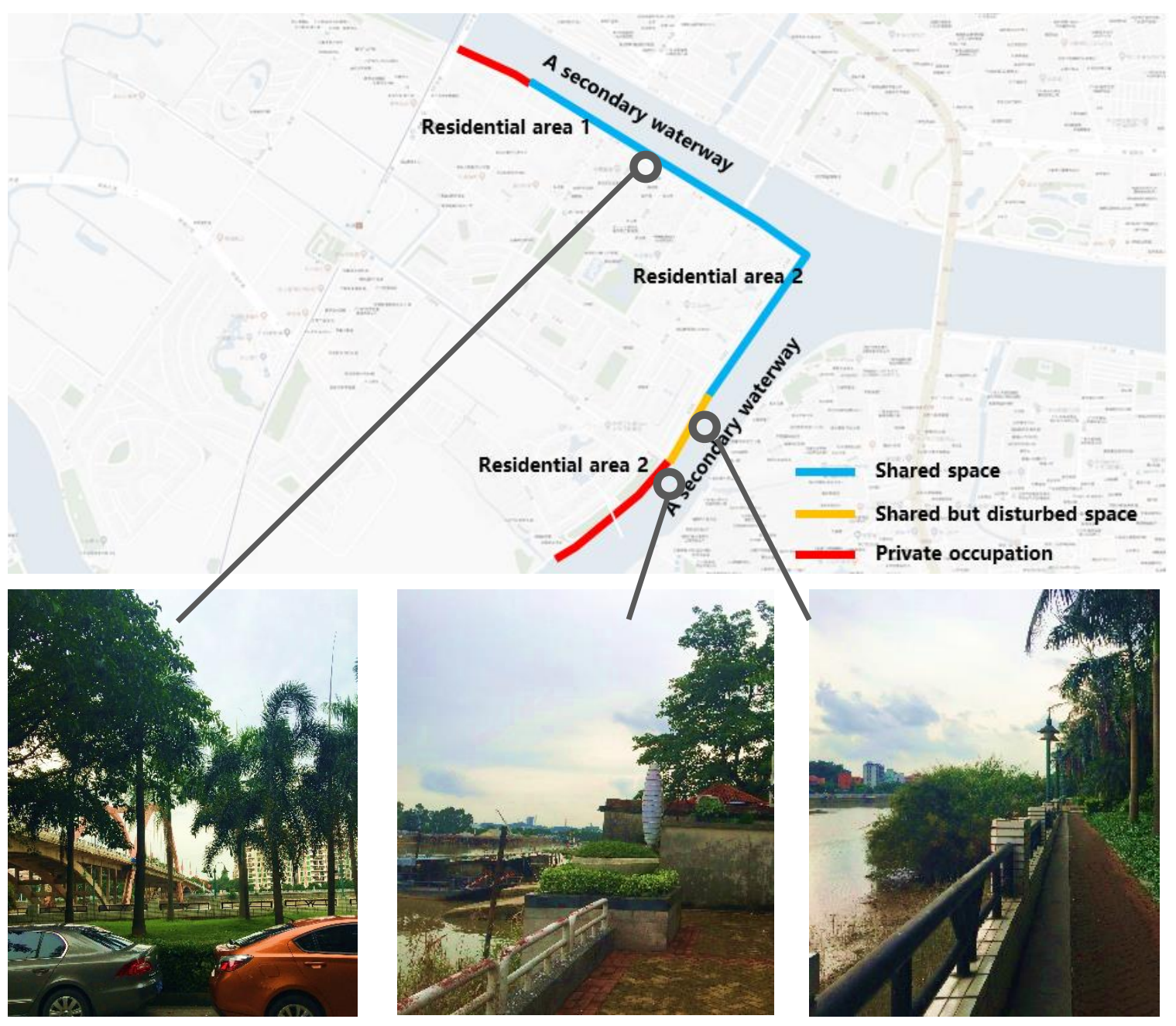

Figure 2. Waterfront space of Dashi river Waterfront. Source: Author self-drawn.

(3) Ersha island

The island is located in the core of the city. There are various important public buildings, technical colleges and high-end residential areas on the island. The island has important waterfront viewing resources in the Pearl River section of Guangzhou, (Fig. 2)and there are also some problems:

- Land package transfer - the waterfront space in the northwest is privately occupied by technical colleges and residential areas;

- Lack of Waterfront Facilities - although most of the waterfront space of Ersha Island is a shareable space, it still lacks sufficient necessary facilities, such as seats, garbage cans, etc. 


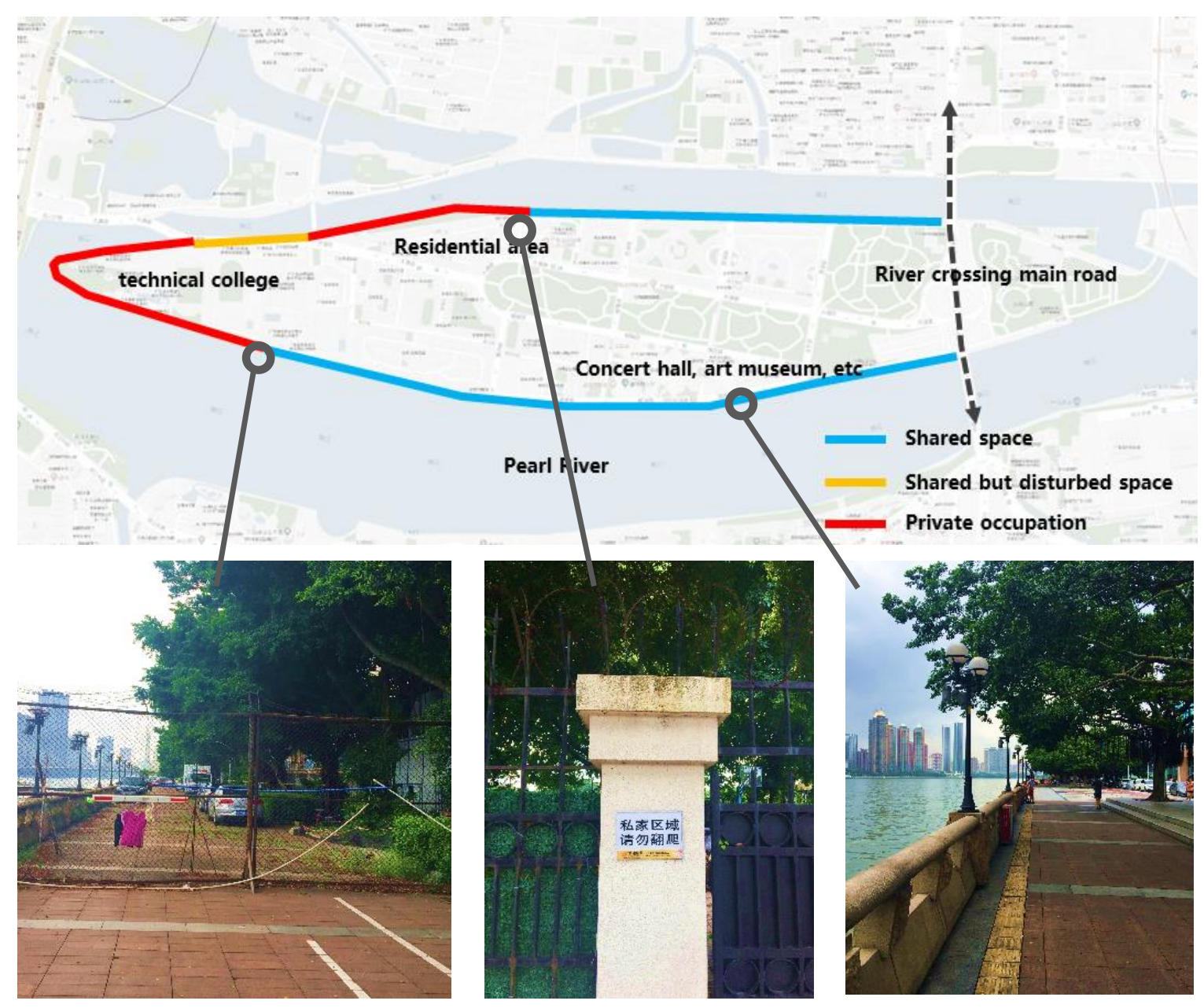

Figure 3. Waterfront space of Ersha island 2. Source: Author self-drawn.

(4) Lijiao river

The island is located in the core of the city. There are various important public buildings, technical colleges and high-end residential areas on the island. The island has important waterfront viewing resources in the Pearl River section of Guangzhou, (Fig.4)and there are also some problems:

- Land package transfer - the waterfront space in the northwest is privately occupied by technical colleges and residential areas;

- Lack of Waterfront Facilities - although most of the waterfront space of Ersha Island is a shareable space, it still lacks sufficient necessary facilities, such as seats, garbage cans, etc. 


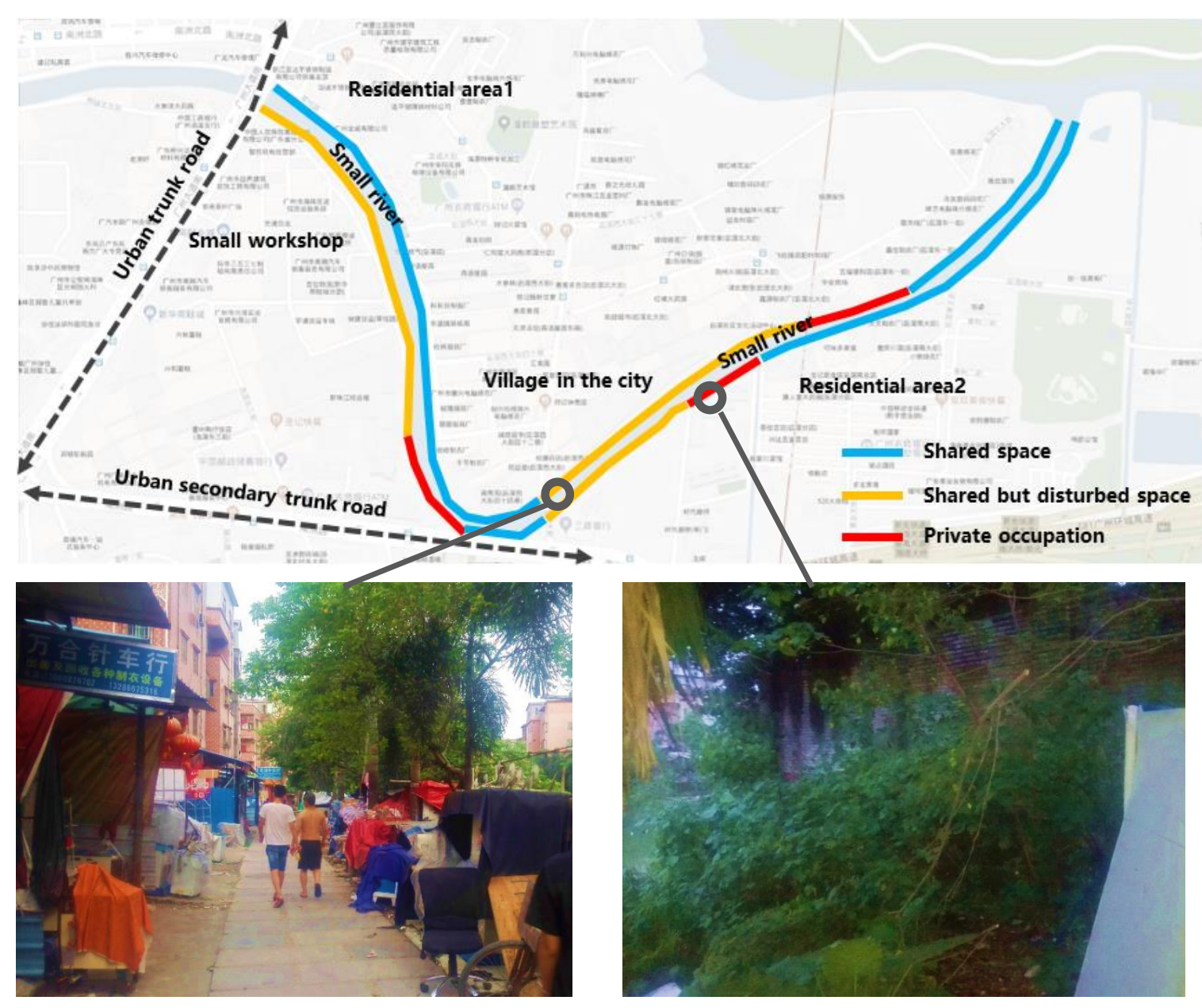

Figure 4. Waterfront space of Liajiao river (He chong). Source: Author self-drawn.

\subsection{Investigation and Analysis}

Although more and more urban managers, scholars and designers have realized the importance of ensuring the publicity of waterfront space, there are still the following problems in the planning, design and control of waterfront public space: first, at the technical level, Waterfront Retreat as the main content is difficult to meet all the connotation of "publicity"; The second is the procedural level, the public as the user is difficult to fully express their demands; The third is the effectiveness level,The current control requirements are lack of mandatory binding force. This makes it difficult for a large number of urban waterfront spaces to enter and use, including the entry problems caused by the strong land occupation of closed communities, major commercial facilities and even service facilities; Improper spatial scale, lack of facilities, negative space, vehicle occupation, interference with surrounding facilities and other use problems.

\section{Reference case}

\subsection{Chicago - Quantitative Management}

Through the formulation of laws and planning and design standards, Chicago of the United States has detailed requirements on the retreat distance of waterfront construction, buildings on both sides of waterfront and the continuity of public space, as follows

- Relevant Chicago municipal regulations stipulate that all development plans within $30 \mathrm{~m}$ on both sides of the urban waterway must be submitted to the Municipal Planning Bureau for review. 
- The Chicago riverside corridor design outline and its standards stipulate that the construction on both banks of any river must be retreated by $9 \mathrm{~m}$ (starting from the top of the shoreline), and only new projects of the river itself are allowed in the "retreated red line" of the Chicago River (referring to the use or practice that can only be implemented in or adjacent to the river).

- There are no requirements for existing buildings in the area requiring retreat, but in order to compensate for the loss of public space along the river caused by insufficient retreat, additional public space must be provided according to the following provisions: for buildings (structures) and private sites with retreat of less than $9 \mathrm{~m}$, public open space must be provided near the retreat area and urban green belt to compensate for the loss of public space along the river, The amount of compensation shall be 2.5 times of the land area occupied in the retreat area, and the ratio of the length of the plot to the width facing the river shall be 2:1, so as to avoid that the plot is too narrow and has no actual interest or use.

- Construction and development area: the riverside facade of the building shall be designed as the main facade of the building, not as the back facade; Green walkway: it should be continuous and interesting.

\subsection{New York - targeted requirements}

Chapter II (a06-c02) of Article VI of the zoning planning regulations of New York is specifically aimed at the zoning planning regulations of the waterfront area, which clearly requires the layout of waterfront pedestrian roads in residential and commercial areas, the waterfront private residential or commercial developers must provide public open space, and the pedestrian roads must be connected with urban streets and parks. (Fig. 5)The following five measures are proposed:

(1) Publicity and maximum sharing of waterfront resources have become the primary principles of waterfront development and design.

(2) Diversity-emphasizing the mixed function of waterfront space, creating a diversified natural environment and providing multi-functional public facilities to provide comfortable living space for citizens.

(3) Openness-waterfront buildings can not block the water landscape corridor, and the visual permeability should be guaranteed.

(4) Accessibility-pedestrian roads are opened along the water body and connected with urban trunk roads to ensure the accessibility of the public.

(5) Conservation-protect the historical, cultural and ecological sensitive areas of the waterfront and the natural resources along the coastline 

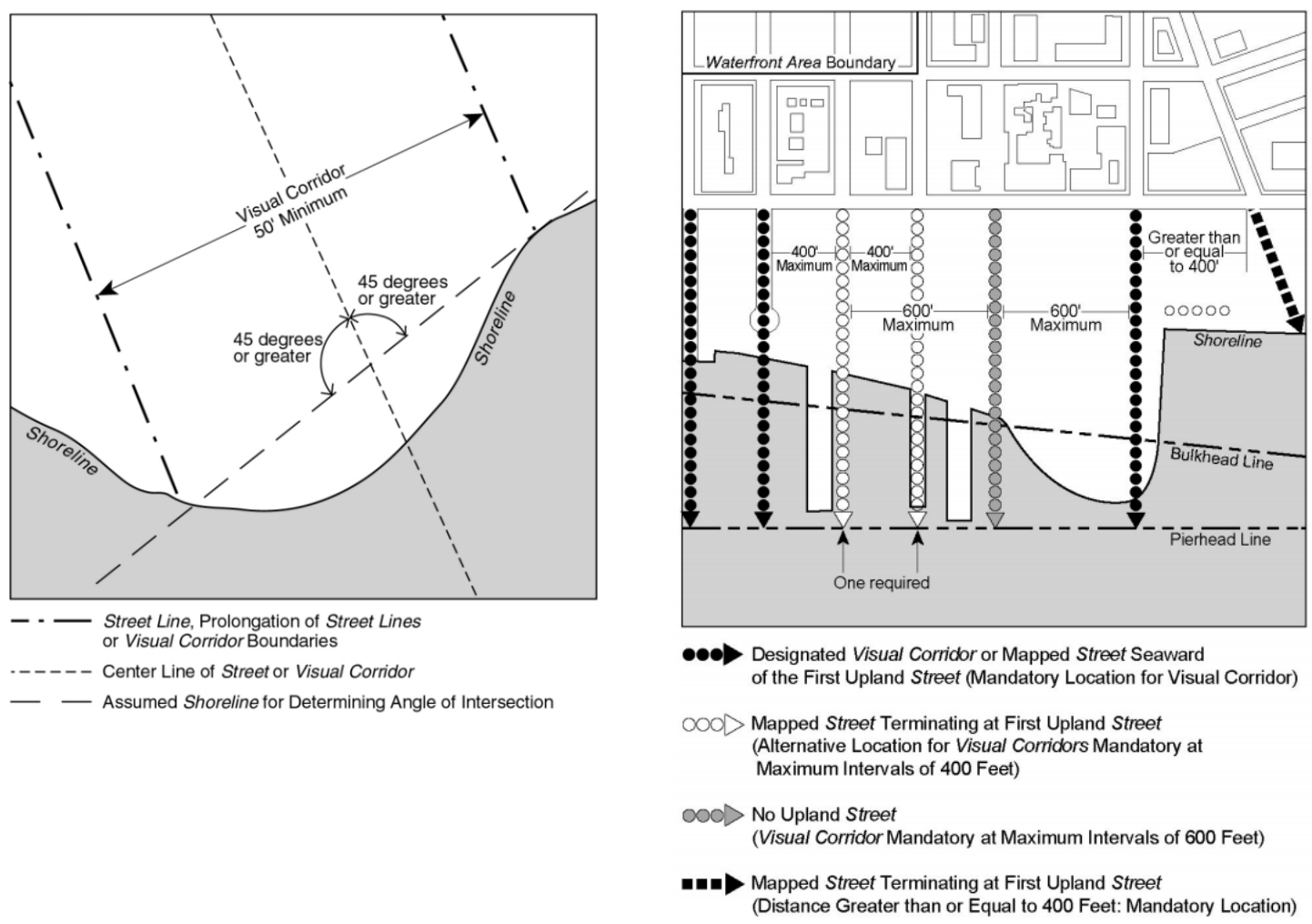

Figure 5. Control diagram of waterfront space corridor in New York. Source: New York Zoning Regulations.

\subsection{Shang Hai - Riverside Linkage Action Plan}

Plan and implement the riverside connection project with "government led, government enterprise cooperation and public participation". The implementation of the project has both a three-year action plan and a longer-term plan. The length is expanded from $21 \mathrm{~km}$ to $45 \mathrm{~km}$. (Fig. 6) The main contents are as follows:

- Objective - to highlight the vertical connection of the riverside space along the riverbank line and the horizontal connection with the riverside hinterland, and to realize the diversity (land mixing), culture (historical connotation) and characteristics (adjusting measures to local conditions) of the riverside public space.

- Build open space carriers such as riverside green space square; Break through the breakpoint and promote the connection of Binjiang public coastline; Construct the riverside slow travel space system; Strengthen the protection and utilization of historical features and industrial heritage resources.

- Optimize the allocation of public service facilities such as commercial catering, culture and entertainment, leisure and sports, tourism services, performances and exhibitions; Improve public parking, public health and other municipal supporting facilities; Improve street furniture, signs, lighting, public art and other environmental landscape facilities according to local conditions.

- Give priority to public transportation and build a transportation network system integrating rail transit, ground bus, water transportation and slow traffic. 

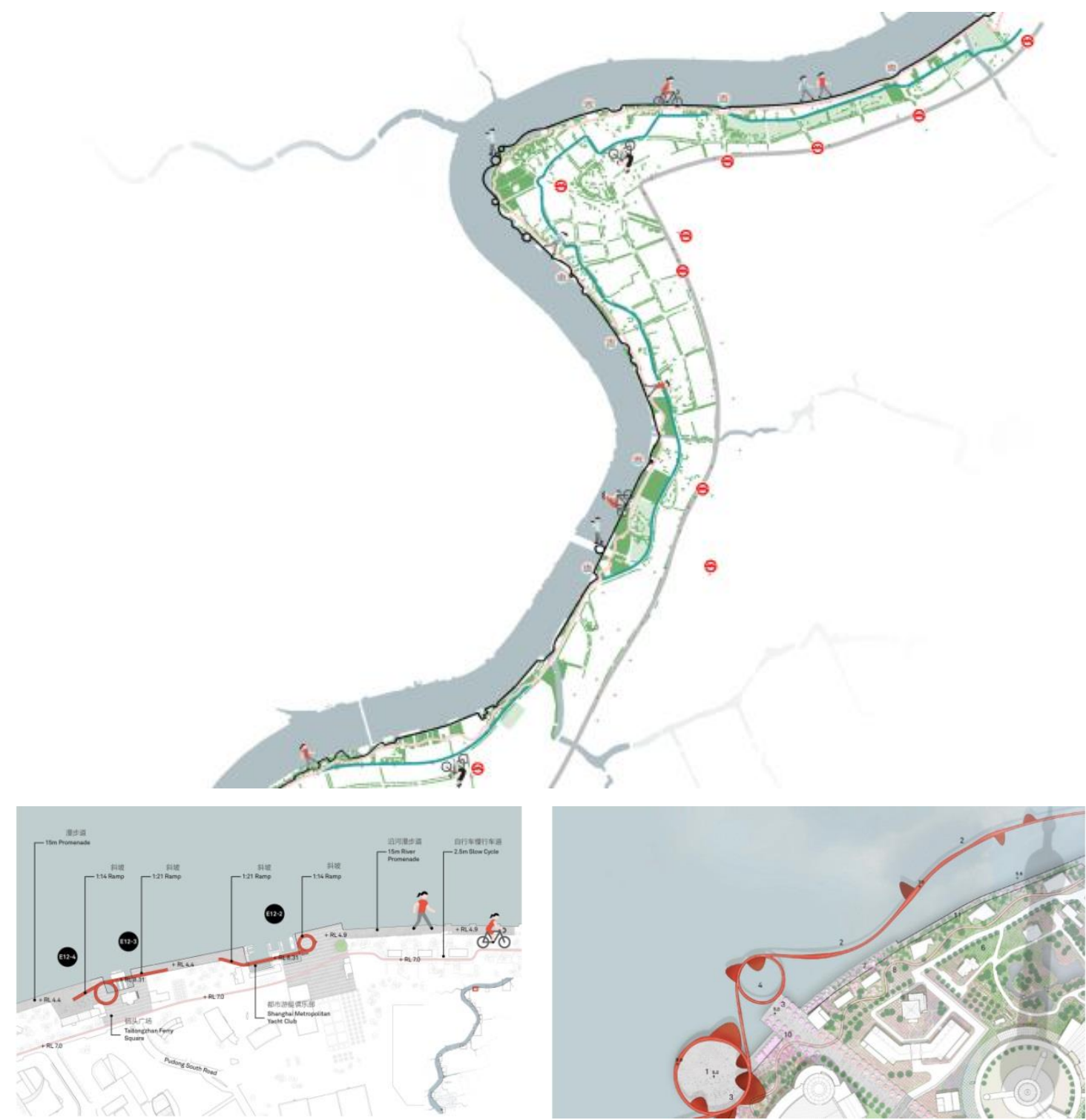

Figure 6. General plan of open space connection planning and design on the East Bank of

Huangpu River in Shanghai. Source: https://www.sohu.com/a/164498508_697365.

\subsection{Sanya -- Based on ecological protection}

The public property of the waterfront space of Sanya River and Linchun River, the main water body of Sanya City, remains good as a whole. The length of the connecting public waterfront space accounts for about $70 \%$ of the total length, which largely benefits from the protection requirements of riverside mangroves. (Fig. 7)The following measures have been taken to protect the waterfront ecology and space of Sanya:

- In 2014, Sanya River and waterfront protection and utilization plan was issued.

- Divide most of the waterfront space into undevelopable areas and functional reserve areas to maintain the public attribute of the original waterfront space area.

- In combination with the suggestions on land use renewal, four lines of blue line, green line, flood control line and mangrove protection line (30M) are defined for the key planning scope, and the development and construction of land resources along the riverbank line are controlled to reserve space for future development. 
- Put forward guidance suggestions on the implementation of management and control for 7 areas, including river environmental protection management and control regulations and waterfront management and control guidance (architectural landscape style guide and street landscape style guide).

- In the "compound" development mode of cooperation between the government and the operating company, the relevant riverside management departments are established to be responsible for the comprehensive environmental improvement of the river, infrastructure construction and maintenance.

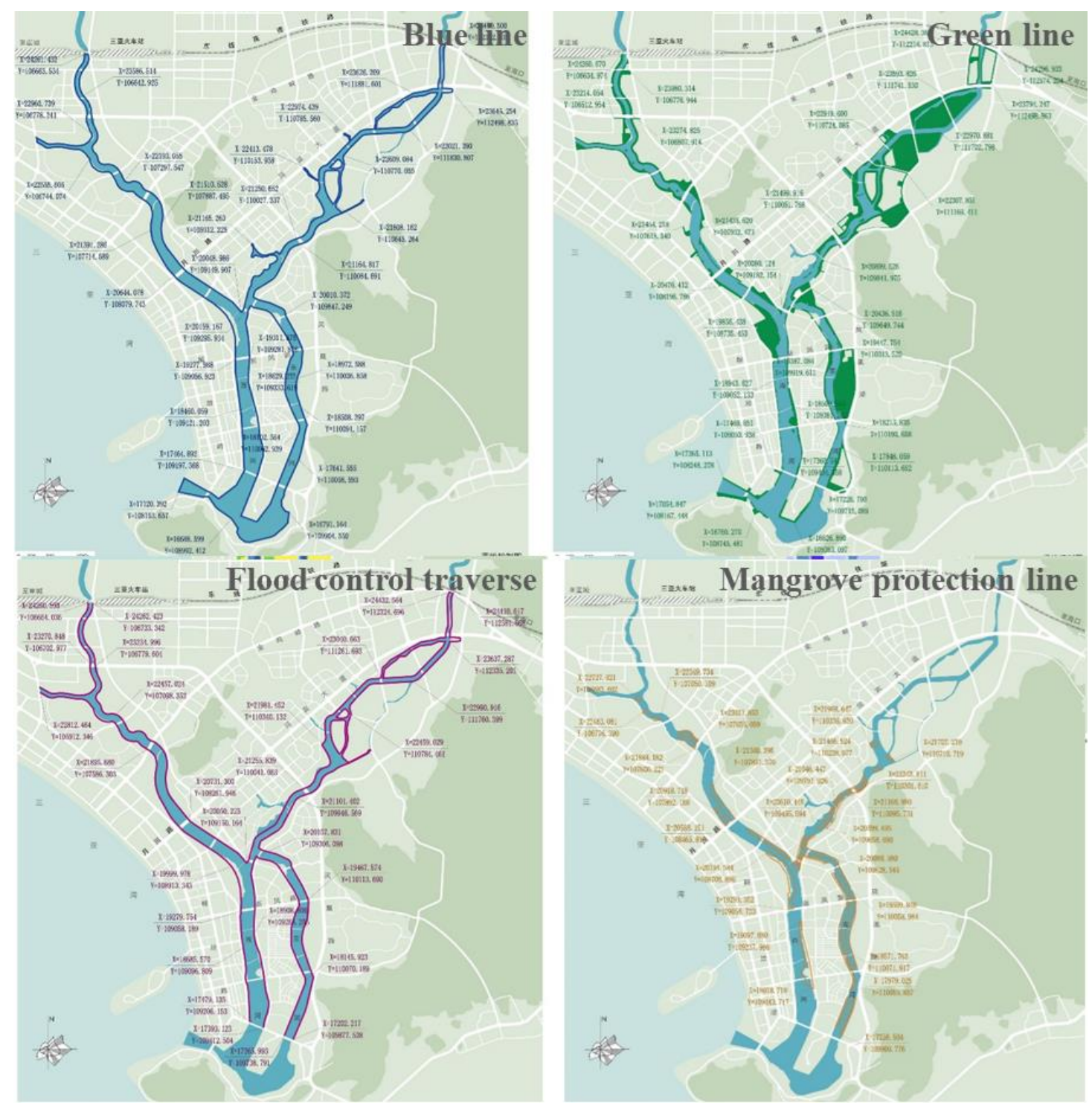

Figure 7. Sanya fourth line control chart. Source: 《Protection and utilization planning of Sanya River and Waterfront》

\section{Establish a planning and control system for waterfront public space}

\subsection{Establish planning control framework}

On the one hand, the construction of the management and control framework of waterfront public space planning needs to focus on the connotation principle of public attribute and meet the core appeal of people-oriented; On the other hand, it is necessary to combine the physical space form characteristics of 
waterfront public space, the consideration composition of internal and external combination and relevant influencing factors. Firstly, public attribute can be further analyzed as accessibility, sharing and suitability. Accessibility is to ensure the free power of the public to "reach" the waterfront space; Sharing is to protect the public's equal right to enter space, use facilities and carry out activities; Suitability is to ensure the free power to meet the public's use demands, feelings and aesthetics when using waterfront space. In order to protect these public free rights, it is necessary to establish control requirements for corresponding space elements. Based on the value pursuit of publicity and the humanistic demands of accessibility, sharing and suitability, this study constructs a waterfront public space management and control framework of "one core, two levels, three objectives and ten control elements" (Fig. 4). Of course, more control elements may be involved in different waterfront public spaces, which need to be further discussed in combination with the actual situation. (Fig.8)

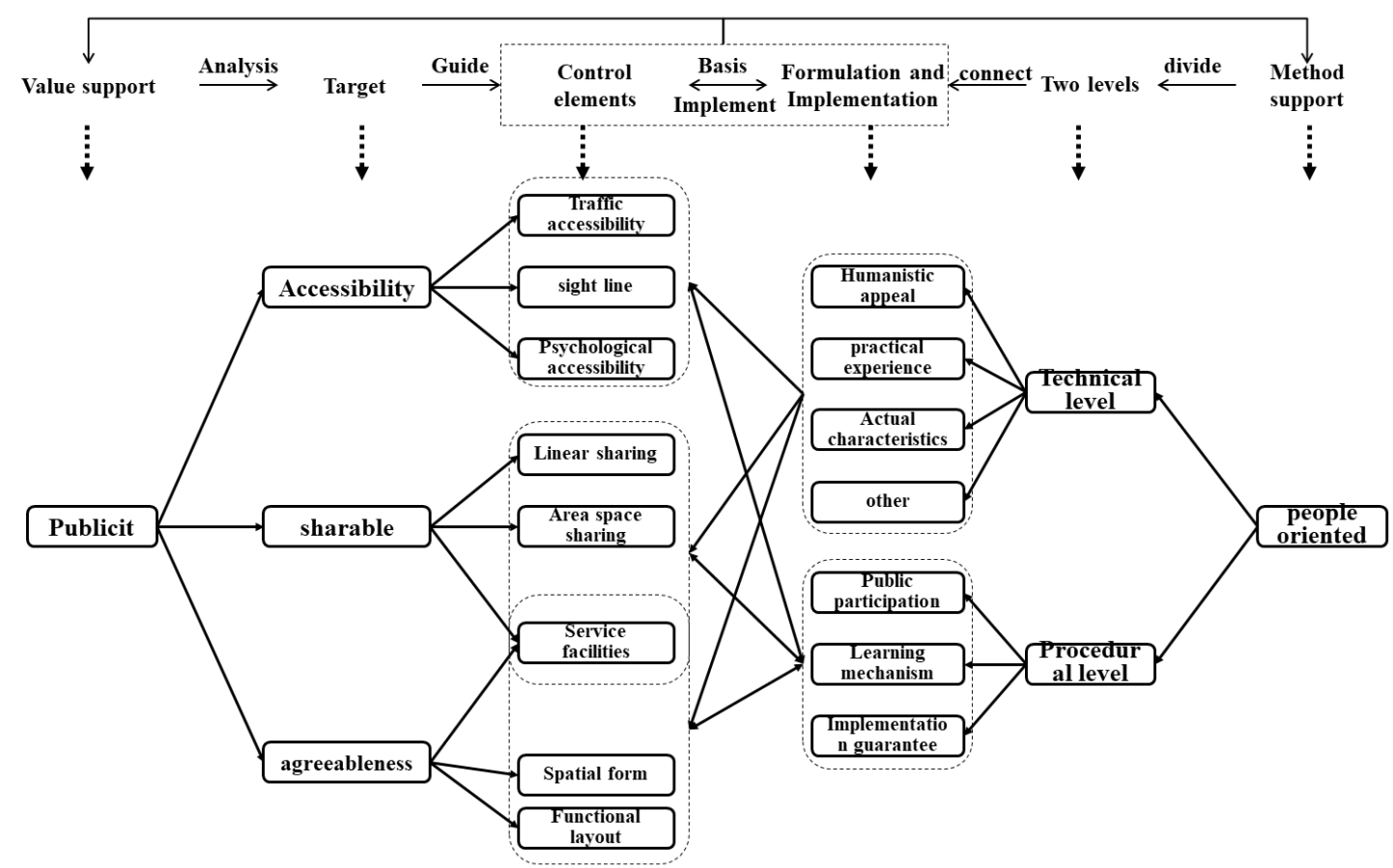

Figure 8. Control element framework of waterfront public space planning. Source: Author self -drawn.

\section{2.research on requirements of planning control elements}

\subsection{1 accessibility}

Accessibility means that the public can easily reach the waterfront public space through a variety of transportation modes such as public transportation, private car transportation, bicycle or pedestrian transportation. This involves the setting of traffic network, public transport stations, parking lots, etc.

Firstly, the semi-network structure road network has the characteristics of equality, selectivity and complexity(Yang,2018). For waterfront cities, the semi-network road network helps to improve the identification and accessibility of River coastal space In recent years, the mode of "small block and dense road network" vigorously promoted in China absorbs the characteristics of semi-network structure road network, and it is suggested to implement relevant standards more strictly in waterfront areas; Then, in order to avoid the division and interference of traffic roads to the waterfront space, the adjacent roads in the waterfront public space should not be set as traffic primary and secondary trunk roads; Public transport and non motorized transport are encouraged on Waterfront roads, and bus lines and bus stops shall be reasonably set on Waterfront roads; According to the experience and relevant specifications, the 
setting of motor vehicle parking lot shall be as close to the waterfront space as possible on the premise of ensuring a safe and comfortable waterfront space environment. It is recommended that the distance from the waterfront space shall not be less than $70 \mathrm{~m}$ and not greater than the width of adjacent waterfront blocks (Fig. 9).

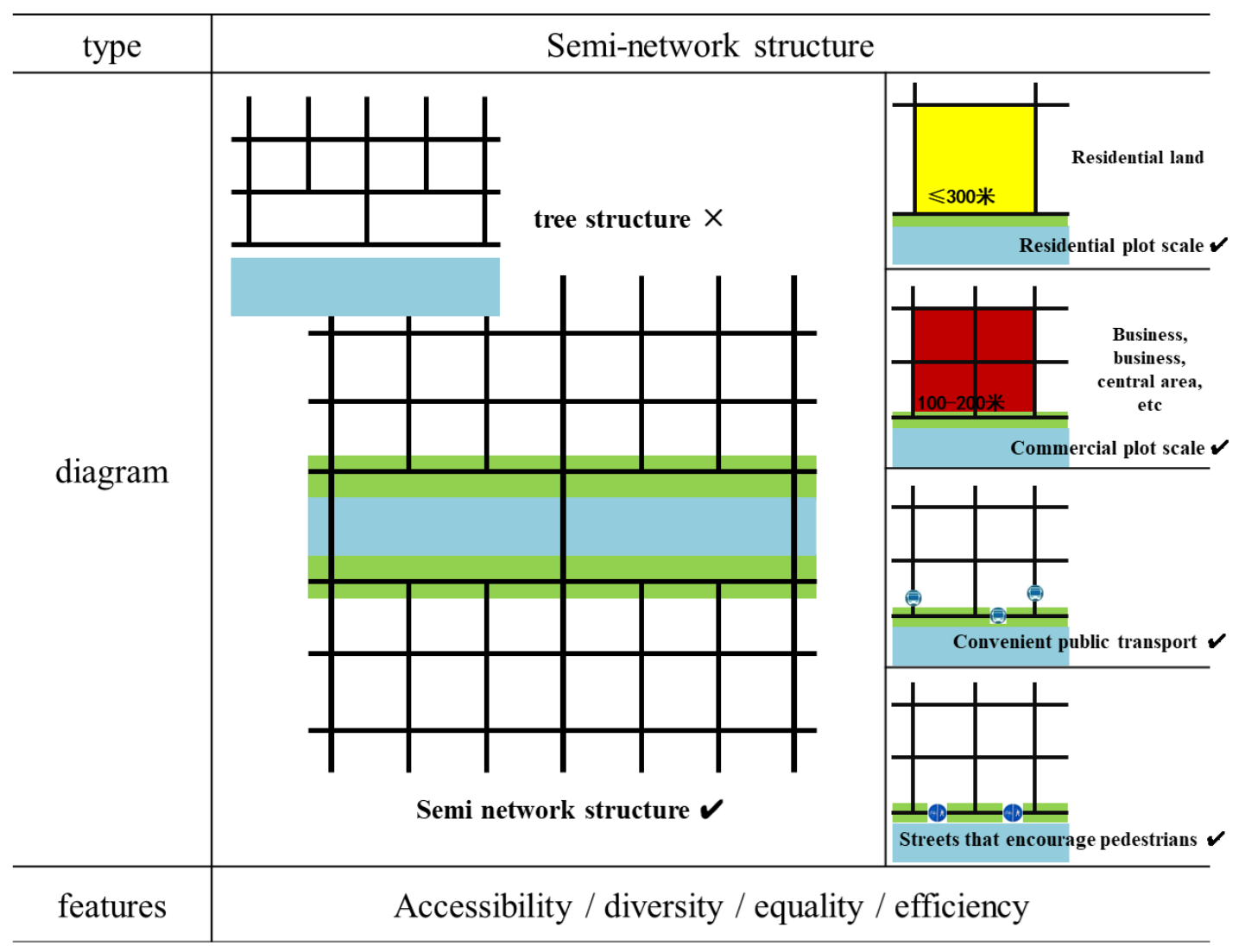

Figure 9. Schematic diagram of accessibility factors for promoting waterfront traffic. Source: Author self drawn.

\subsection{2 visual accessibility and waterfront entrance rate}

Visual accessibility means that more public can share public landscape resources through vision by retaining or opening up the visual corridor leading to the water body. In combination with human visual characteristics, on the longitudinal viewing gallery, viewing gallery shall be mandatory for plots within $270 \mathrm{~m}$ from the water body, and it is recommended to set viewing gallery for plots within $500 \mathrm{~m}$; For the horizontal spacing between viewing galleries, it is recommended to refer to what is done in New York and in combination with the recommended scale value of "small block and dense road network" in China. It is recommended to set at least one water viewing gallery within the plot with a width of less than 300 meters, and consider the setting of pedestrian walkways. ( Figure 10)

Reasonable waterfront entrance rate setting can effectively coordinate the natural landscape and artificial landscape, so that the waterfront public space and waterfront plot can obtain better environmental and landscape effects. At present, there is no special research or requirement for waterfront inter port rate in China. In the waterfront planning of Kobe City, Japan, the inter outlet rate is required to be less than $7 / 10$,(Jin,1994) and the inter outlet rate of high-quality urban waterfront space at home and abroad generally will not exceed $76 \%$. Therefore, it is recommended to take $76 \%$ as the upper limit of the inter outlet rate, and then further determine the specific inter outlet rate by classification in combination with the waterfront space location and the nature of surrounding land. 


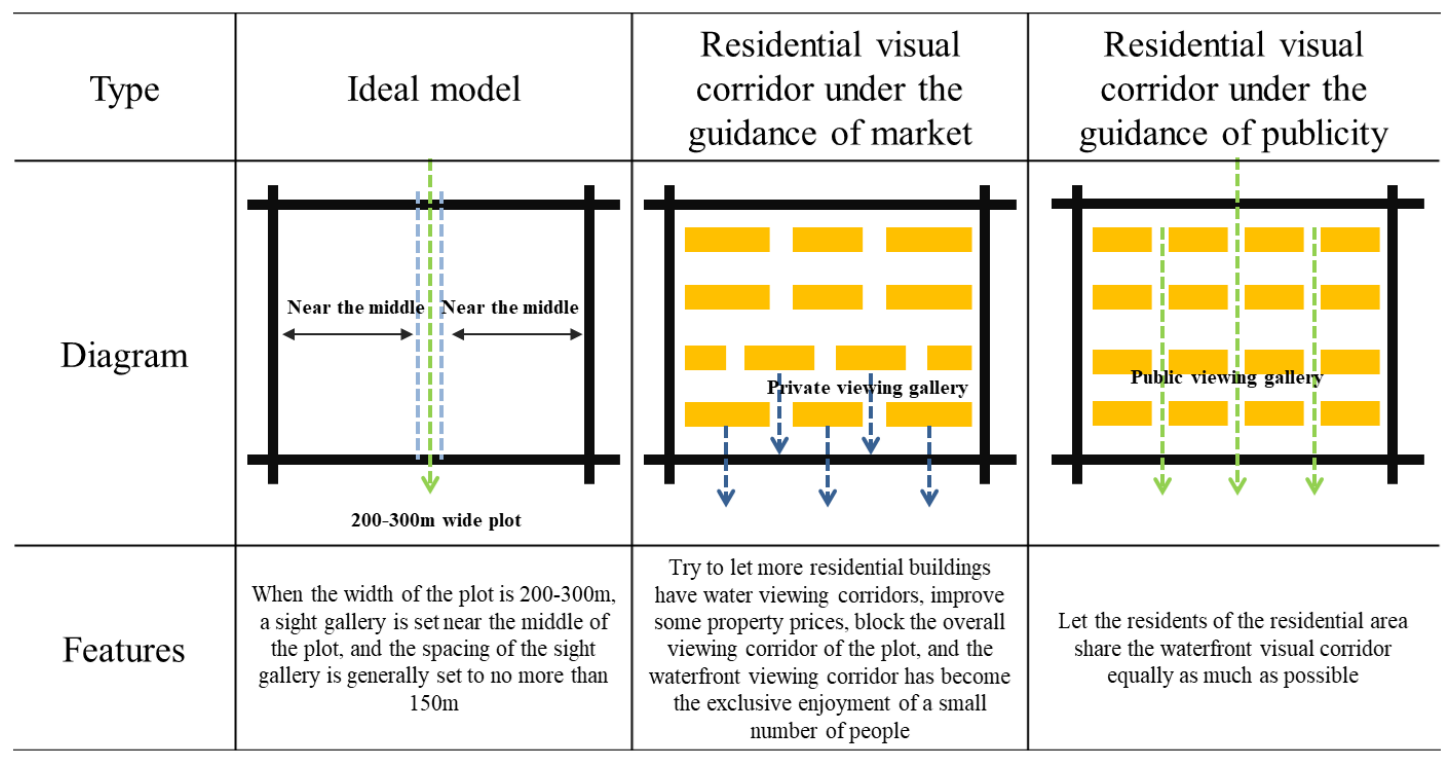

Figure 10. Promoting visual accessibility pattern map. Source: Author self-drawn.

\subsection{3 psychological accessibility and waterfront interface}

Waterfront public space should avoid giving the public accessible material space conditions, but it also brings psychological exclusion to the public, which makes them unwilling to enter. The elements that may cause public psychological exclusion in waterfront public space generally include water pollution, negative space, management and safety problems, etc,

Whether the waterfront public space is close to harmful or disturbing urban functional facilities is also an important factor affecting the psychological exclusion of the public. Firstly, the water environment should reach the level that can be directly contacted by human body; Then, in terms of management, coastal residents or merchants are not allowed to pile up garbage and shelve personal belongings at will in the waterfront public space. To solve this problem, we need to explore the responsibility mechanism, reward and punishment mechanism jointly managed by the government and the property owners and users around the waterfront space; Finally, in terms of safety, it is mainly necessary to ensure the personal safety of the public and avoid malignant events endangering public life and property through the reasonable setting of waterfront protection facilities, life-saving facilities, monitoring facilities and public security police force.

The waterfront boundary has an important impact on the feelings of users. The waterfront interface mentioned in this paper refers to the boundary between the waterfront public space area and the nonpublic space area. It can be in the form of buildings, structures, greening and other interface forms. The setting of the waterfront interface should be based on the principle of building positive space, avoiding negative space and avoiding mutual interference on both sides of the interface, It is recommended that the commercial and public service facility interfaces and greening interfaces with strong interaction with the outside world and opening to the outside world be reduced, and the closed or easily interfering wall, residential and other interface forms are reduced.

\subsubsection{Building red line and height}

The demarcation of the backward red line of waterfront buildings should be based on people's feelings, combined with the width of water body, the control height of waterfront buildings, the number of users, (Gehl,2009) etc. In the actual activity experience, $18^{\circ}-45^{\circ}$ is the ideal viewing area(Li,2008), and the value range of building spacing and building height corresponding tois 1:1-3:1(Jan,2002), while it is generally considered that the ratio of building spacing to building height is $6: 1$ as the upper limit ratio of viewing buildings; At the same time, the sight distance within $25 \mathrm{~m}$ is the "meeting" of "really interesting" 
and has social significance, while the sight distance of $100 \mathrm{~m}$ is the visual social boundary[ 11] Based on the above conclusions, this study takes $25 \mathrm{~m}$ and $100 \mathrm{~m}$ as the boundary, and considers the assignment of Waterfront Retreat red line in three cases (Table 1). In view of the correlation between height and width, empirical calculation shows that when discussing the first case, if the minimum value of Waterfront Retreat red line cannot be determined in advance, the next calculation cannot be carried out. Therefore, this paper puts forward the concept of "primary public unit" of waterfront public space, and takes the width of "primary public unit" as the minimum value of Waterfront Retreat red line.

\begin{tabular}{l|l}
\hline \multicolumn{1}{c|}{ classification } & \multicolumn{1}{c}{ Assignment scope } \\
\hline $\begin{array}{l}\text { When the distance between the waterfront } \\
\text { surfaces of the first row of buildings on both } \\
\text { banks is less than or equal to } 25 \mathrm{~m}\end{array}$ & The water body and waterfront space are studied as a whole \\
\hline $\begin{array}{l}\text { When the distance between the waterfront } \\
\text { surfaces of the first row of buildings on both } \\
\text { banks is greater than } 25 \mathrm{~m} \text { and less than or } \\
\text { equal to } 100 \mathrm{~m}\end{array}$ & $\begin{array}{l}\text { The relationship between the retrogression of unilateral } \\
\text { waterfront space and the building height shall be considered, } \\
\text { and the lower limit of the echo relationship between the } \\
\text { buildings on both banks shall also be considered }\end{array}$ \\
\hline $\begin{array}{l}\text { When the distance between the first row of } \\
\text { buildings on both banks is greater than } 100 \mathrm{~m}\end{array}$ & $\begin{array}{l}\text { Only the ratio of single side building spacing to building height } \\
\text { is considered }\end{array}$ \\
\hline
\end{tabular}

Table1. Waterfront receding classification. Source: Author self-drawn.

The so-called "primary public unit" (Fig. 11)means that when the minimum number of people enter the waterfront public space, their basic demands such as safety, passage and stay can be guaranteed. In terms of space composition, "primary public unit" shall be composed of activity space, greening space and facility space, in which the activity space shall at least meet the requirements of two-way traffic and stay. Generally speaking, the width of two-way traffic for one person or bicycle is $2.5 \mathrm{~m}$, while the width of space for two people to stay and exchange is $2 \mathrm{~m}$, so the width of activity space shall not be less than $4.5 \mathrm{~m}$; The greening space plays a basic role in beautifying, protecting and dividing the space. Its width is calculated according to the standard width of the tree pool of $1.5 \mathrm{~m}$. In order to save space as much as possible, seats, garbage cans, street lamps, etc. can be arranged in combination with the greening space; It can be seen from the above that the width of the "primary common unit" (Fig. 7) is $6 \mathrm{~m}$ " "Primary public unit" is suitable for solving the public problems of waterfront public space in old

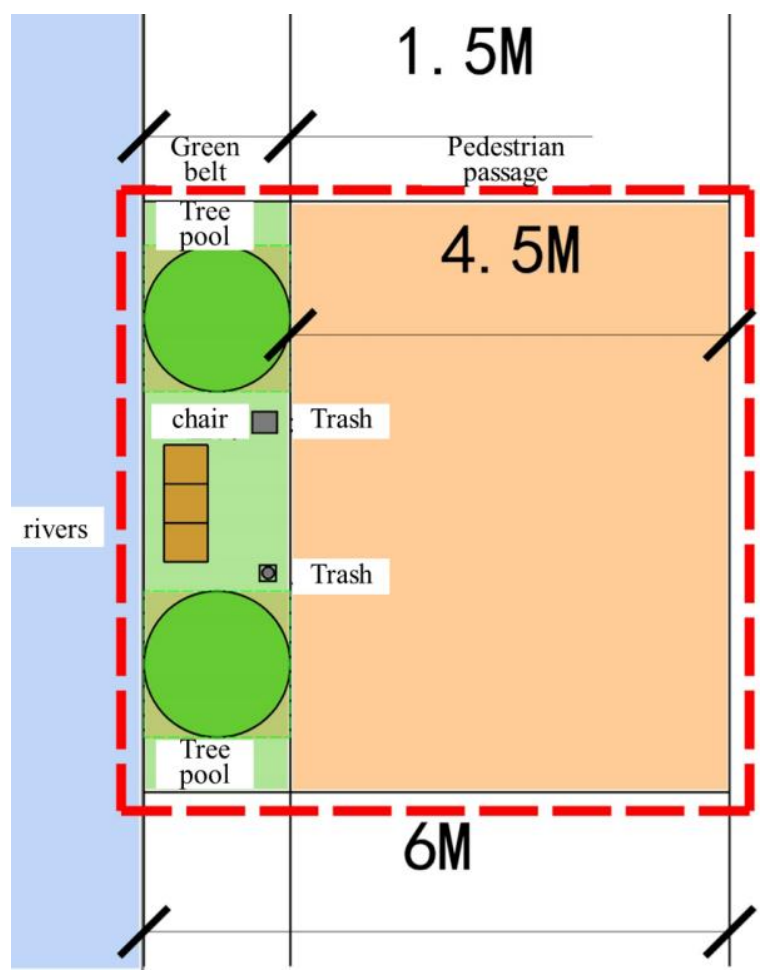

Figure 11. Basic common unit. Source: Author self-drawn. cities or other built-up areas with limited land and great reconstruction difficulty. 


\subsubsection{Node open space}

Due to different sections and distances, the number of public and activity demands carried by the waterfront space will be different. The equal space reserved by the Waterfront Retreat red line is not enough to meet the public needs. It is required that the spatial scale, facility type and quantity of some locations of the waterfront public space have higher standards, The interspersed node open space can effectively meet more public demands. (Fig. 12)

Generally speaking, if people walk more than 400-500m, they need to rest, stay, communicate and other activities. Therefore, the setting spacing of node open space should not exceed 500m (Fig. 8). It can be arranged in combination with important public buildings, waterfront space entrances and exits, viewing platforms and other service facilities.

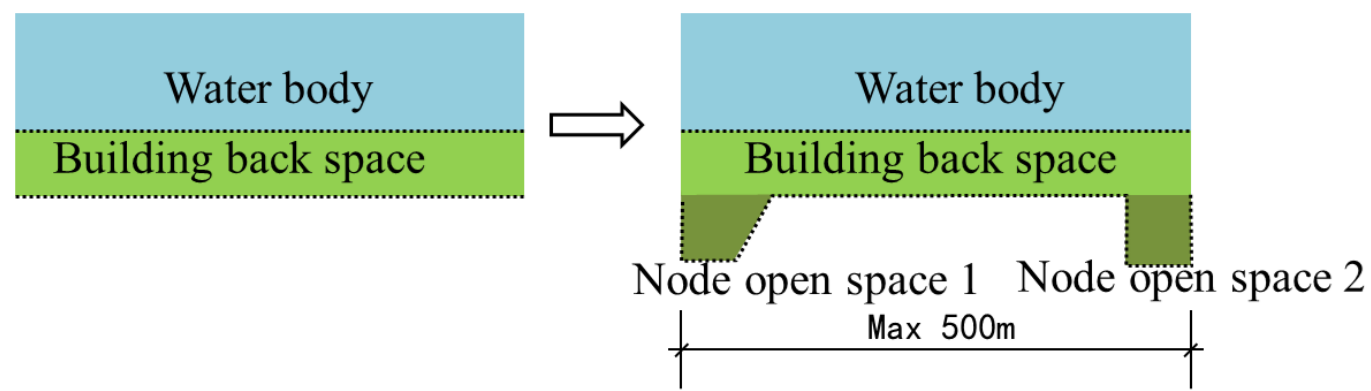

Figure 12. Schematic diagram of open node space control. Source: Author self-drawn.

\subsubsection{Service functions and facilities}

The land and facilities adjacent to the waterfront public space have a significant impact on the use of the waterfront space. Combined with the public opening attribute of the leading function of the land, the impact on the waterfront environment and other impacts on the public use of the waterfront public space, the waterfront land is divided into three levels: suitability level, compatibility level and exclusion level[ 12] When the land function has obvious public open attribute, can promote the shared use of waterfront public space, and can make better use of waterfront environment, it is "appropriate level". This kind of land includes land for cultural facilities, land for sports, land for social welfare facilities, land for religious facilities, land for commercial service facilities, land for green space and square. In addition, open residential areas Mixed commercial and residential land should also be included in the "suitability level"; When the dominant function of urban land is semi public or private, can better realize the market value of waterfront space, and has no negative impact or small negative impact on the waterfront environment, this kind of land belongs to "compatibility level", which includes ordinary residential land, administrative office land, education and scientific research land, foreign affairs land, etc; When the activities of urban land exclude the waterfront publicity, interfere with the progress of waterfront public activities or damage the waterfront environment, such land belongs to the "exclusion level", which includes industrial land, logistics and storage land, urban primary and secondary traffic road land, supply facility land, environmental facility land and other public facility land, Such land should not be arranged in waterfront areas that emphasize the vitality of people.

Service facilities are necessary to meet the needs of the public. Relevant research shows that the three favorite waterfront public space activities of the public are walking, sitting idle and watching the scenery. In the process of these activities, basic demands such as going to the toilet, throwing garbage, identifying the road, drinking water and safety will be derived. Corresponding facilities need to be set in waterfront public space to meet relevant demands. These facilities shall include rest seats, various signs, dustbins, drinking water devices, toilets, guardrails, monitoring facilities, lighting facilities, barrier free facilities, 
etc., among which various signs include location and guidance signs, safety signs, barrier free signs, etc; The distance between dustbins shall not be greater than $200 \mathrm{~m}$; The spacing between drinking water devices shall not be greater than $250 \mathrm{~m}$; The service radius of toilet shall not be greater than $250 \mathrm{~m}$; The number of rest seats can be set at $20 \% \sim 30 \%$ of the tourist capacity according to the provisions of code for design of parks (GB 51192-2016); Other facilities shall be set according to relevant national standards and specifications. In addition, the waterfront public space can also be equipped with sun shading and rain protection facilities, bicycle parking, management office, small business, medical assistance, automatic sales, game fitness, hydrophilic platform and other facilities according to the actual needs.

\section{4 implementation strategy}

\section{1 system guarantee}

Build an institutional system from the national to local levels, and incorporate relevant technical contents into the urban and rural planning management and control system. The administrative measures for urban design launched and implemented by the Ministry of housing and urban rural development in June 2017 specifies that "waterfront areas" should prepare "key urban area design", and local cities should take the initiative to connect with the above urban design programmatic documents by incorporating the elements of waterfront public rational control into the local "technical regulations for urban and rural planning" or "urban design management regulations", Then guide the implementation of regulatory detailed planning. It is worth noting that waterfront public space, as the embodiment of public interests, requires in-depth public participation and expression in the planning and construction process. However, at present, the level of public participation still needs to be improved, the awareness of public participation is relatively weak (Sun,2011), and there is a lack of in-depth communication in the planning process.(Li,2008)

\section{2 implementation strategy}

The implementation of waterfront public space planning control content requires targeted measures from the control area and control function. In terms of control areas, there are great differences in the problems and improvement difficulties faced by the waterfront public space between the new area and the built area. For the newly-built area, it can be limited and pre controlled through regulatory detailed planning and urban design, so as to implement the relevant requirements; For the built-up area, it may face more complex situations. The implementation strategy of "gradual renewal" or "active governance" should be adopted with the goal of implementing the control requirements at the control level" "Gradual renewal" means that when it is difficult to make a breakthrough in the current problems, it will be implemented gradually according to the control requirements when the area needs to be renewed and transformed in the future" "Active governance" can be to take effective measures for the waterfront space with many demands for urban public activities and the coordination of all stakeholders. "Active governance" is a strong comprehensive governance; It can also be adjusted only locally, such as opening the occupied waterfront public space of the community in different periods, changing the occupied space into semi-public space, or environmental remediation in accordance with the requirements of "primary public unit".

From the perspective of management and control function, the realization of "public rationality" of waterfront public space not only involves space management and control, but also is closely related to public security management, water body governance and other environmental governance. It requires the cooperation of multiple functional departments, improve public participation and formulate relevant cooperation, reward and punishment mechanisms. 


\section{Conclusion}

As a typical public space with natural publicity, resource scarcity and great value, urban waterfront public space is an important element to improve the quality of public life of urban residents. This paper believes that in view of the violation of publicity and rational loss faced by urban waterfront public space, it is necessary to technically clarify the planning framework of public elements and its control requirements, Only by connecting the system and implementing the policy in the implementation can we solve the practical problems and show the real value of waterfront public space.

\section{References}

Gehl, J.(2002)Life Between Buildings. 3rd edn.Beijing: China Construction Industry Press.

Jin,G.J. (1994) 'Planning and design of urban waterfront in Japan', City Planning , 18(4), p45-49.

Li,S.F.,Zhang,J.(2008)'Analysis on the organic composition of buildings and external space', Time Architecture,6, p104-107.

Liu,M.B.(2018) 'The key to development lies in water: the era of urban waterfront is coming', City Planning,42(3),p72-79.

Mitchell, J.A. 'How citation changed the research world', The Mendeley, 62(9), p70-81.

Qian,F.(2010) 'Analyzing the constituent elements of urban waterfront space from the perspective of health orientation', Architectural Journal,11, p 80-85.

Song,W.X.,Zhu,X.G.,Wu,Q.Y.(2010)'Planning and protection of public rights and interests in urban waterfront space', City Planning , 24(10), p43-47.

Song,W.X.,Zhu,X.G.,Wu,Q.Y.(2010)'Benefit and equity of urban waterfront space production -- a case study of Nanjing' , Urban Planning International | Urban Plan Int ,24(6), p 66-71.

Sun,S.X. (2011)Garden art and garden design. 1st edn. Beijing: China Construction Industry Press.

Yang,C.X.,Shi,M.,Geng,H.Z.(2018)'Study on Waterfront pedestrian accessibility based on the interpretation of urban texture level-a case study of Suzhou River Estuary in Shanghai', City Planning ,42(2), p 104-114. 